\title{
Research on Talent and Urban Development Strategy
}

\author{
Mingchun Shi, ${ }^{1,}$, Junhao Zou ${ }^{2, *}$, Zhuoyang Wang ${ }^{2, *}$, Xinyu Zhang, , , Haoyu Zhang ${ }^{2, *}$ \\ ${ }^{1}$ Department of Economic Management, Harbin University of Science and Technology, Weihai City, China \\ ${ }^{2}$ Department of Electrical, Harbin University of Science and Technology, Weihai City, China \\ Email address: \\ 1315645766@qq.com (Mingchun Shi),1754659246@qq.com (Junhao Zou), 1091691151@qq.com (Zhuoyang Wang), \\ 168341731@qq.com (Xinyu Zhang),727990268@qq.com (Haoyu Zhang) \\ ${ }^{*}$ Corresponding author
}

\section{To cite this article:}

Mingchun Shi, Junhao Zou, Zhuoyang Wang, Xinyu Zhang, Haoyu Zhang. Research on Talent and Urban Development Strategy. International Journal of Economics, Finance and Management Sciences. Vol. 7, No. 6, 2019, pp. 203-209. doi: 10.11648/j.ijefm.20190706.14

Received: October 31, 2019; Accepted: November 25, 2019; Published: December 3, 2019

\begin{abstract}
The imbalance between talent supply and demand is a basic problem in today's society, and the degree of deployment between talent pool and talent and occupation in cities also affects the development of cities. Therefore, it is of great significance to grasp the relationship between talents and the relationship of development. First of all, according to different categories of talent, the talent demand model with multi-objective analysis level process (ahp) is established, and the current situation of the talent market is analyzed from three aspects: job demand, expected occupation and educational background requirements. Secondly, the Alima model of talent demand forecasting and analysis is established, and combined with the time series model to predict the potential talent demand of future cities, and conclude that the most important needs of professional in the next three years are economic management, and the most important need for work is science and technology. Finally, according to the current situation of college students' different professional preferences, the Garch model is established, the strategy of urban development and talent introduction is put forward, and reasonable test is carried out, and the corresponding reasonable strategy of matching supply and demand between talents and cities is given, the imbalance between talent supply and demand is reduced, and the development of the city is improved.
\end{abstract}

Keywords: Talent Demand, Arima Model, Garch Model

\section{Introduction}

Faced with the opportunities and challenges brought by economic globalization, the demand for talents is the biggest manifestation of urban vitality. Therefore, it is necessary according to the characteristics of the city and the characteristics of different careers, to explore basic dimensions of talent attraction, hierarchy, internal structure and the main connotation, and gives the corresponding evaluation index, including: depending on the work demand, can be divided into economic management, science and technology, social security, service class and other classes; According to the different educational background can be divided into undergraduate education above, undergraduate education below and no requirements for education.

Yu Fei, Wang Huiqiang [1] and others constructed the index system of urban talent attractiveness evaluation from three dimensions, such as economic environment level, science and technology education environment level and social environment level in 2017, and made a detailed analysis by factor analysis. Chen Lei [2] used the hierarchical analysis method in 2018 to establish an evaluation index system that affects the attractiveness level of urban talents, and quantitatively studied the level of urban talent attraction. Zheng Wei, Huang Xing, Xiao Yujie [3] and others accurately predicted the sales demand of e-commerce enterprises in 2019 with the aid of the Arima model, providing a. a set of ideas.

\section{Talent Demand Evaluation}

Analytic Hierarchy Process (AHP) is a decision making method that decomposes the elements always related to decision into the levels of objective, criterion and scheme, and makes qualitative and quantitative analysis on this basis. The following steps are taken to study the demand for talents by AHP: 


\subsection{Analytic Hierarchy Process}

\subsubsection{Constructing the Evaluation Index System of Urban Talent Demand}

The evaluation index system of urban talent demand [4] is shown in Table 1.

Table 1. Talent demand evaluation index.

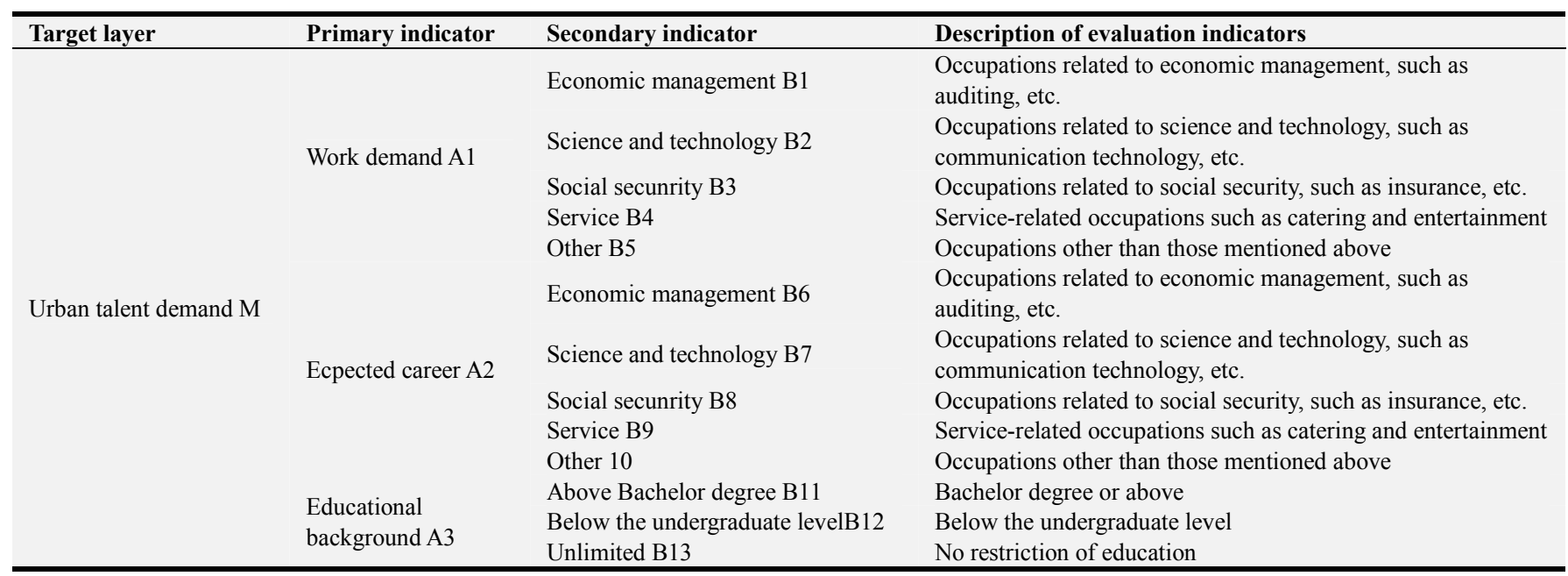

\subsubsection{Construction of Judgment Matrix}

By using the method of pairwise comparison, the pairwise comparison of each related index is carried out. According to some indexes in the middle layer, the matrix $\mathrm{B}$ and $\mathrm{C}$ of several pairwise comparisons can be obtained. For the ratio of pairwise comparison, the scale method of 1-9 is used.

\subsubsection{Weight Calculation}

After the judgment matrix is established, the characteristic root and eigenvector satisfying $B W=\lambda \max W$ are calculated for the judgment matrix $B$, where $\lambda$ max is the largest eigenvalue of $B$. $W$ is the normalized eigenvalue corresponding to $B$, and the component of $W$, that is, the single ranking weight of the corresponding index.

\subsubsection{Consistency Test}

Since it is difficult to ensure complete consistency when comparing multiple indexes, it is necessary to check consistency. In order to verify the consistency of judgment matrix, the consistency index CI should be calculated. The Formula of $C I$ is: $C I=\lambda-n / n-1$, The larger the $C I$, the greater the inconsistency. Definition consistency ratio $C R=C I / R I$, When $C R<0.1$, the consistency test is passed, otherwise the judgment matrix needs to be adjusted.

\subsection{Discussion and Results}

\subsubsection{Solution of Analytical Hierarchy Process}

(1) Target level judgment Matrix

Table 2. Talent demand $M$.

\begin{tabular}{lllll}
\hline M & A1 & A2 & A3 & Weight \\
\hline A1 & 1 & $1 / 4$ & $1 / 3$ & 0.1220 \\
A2 & 4 & 1 & 2 & 0.5584 \\
A3 & 3 & $1 / 2$ & 1 & 0.3196 \\
\hline
\end{tabular}

$$
\lambda=3.0183, C I=0.0091, R I=0.58, C R=0.0158<0.1
$$

According to the judgment matrix of talent demand in Table 2 , the maximum eigenvalue is 3.018 , the consistency index is 0.091 , and the consistency ratio is 0.016 by comparing with random consistency index 0.58 .

(2) Primary evaluation index judgment matrix

Table 3. Work demand A1.

\begin{tabular}{lllllll}
\hline A1 & B1 & B2 & B3 & B4 & B5 & Weight \\
\hline B1 & 1 & 3 & 5 & 7 & 8 & 0.5229 \\
B2 & $1 / 3$ & 1 & 2 & 2 & 6 & 0.2127 \\
B3 & $1 / 5$ & $1 / 2$ & 1 & 2 & 3 & 0.0818 \\
B4 & $1 / 7$ & $1 / 2$ & $1 / 2$ & 1 & 2 & 0.0818 \\
B5 & $1 / 8$ & $1 / 2$ & $1 / 3$ & $1 / 2$ & 1 & 0.0579 \\
\hline
\end{tabular}

$$
\lambda=5.3930, C I=0.0983, R I=1.12, C R=0.087<0.1
$$

According to the work requirement judgment matrix obtained in Table 3, the maximum eigenvalue is 5.3930 and the consistency index is 0.0983 using matlab software, and the consistency ratio is 0.087 by comparing with random consistency index 1.12 .

Table 4. Expected career $A 2$.

\begin{tabular}{lllllll}
\hline A2 & B6 & B7 & B8 & B9 & B10 & Weight \\
\hline B6 & 1 & 4 & 6 & 8 & 8 & 0.5798 \\
B7 & $1 / 4$ & 1 & 2 & 3 & 4 & 0.1883 \\
B8 & $1 / 6$ & $1 / 2$ & 1 & 2 & 3 & 0.1150 \\
B9 & $1 / 8$ & $1 / 3$ & $1 / 2$ & 1 & 2 & 0.0699 \\
B10 & $1 / 8$ & $1 / 4$ & $1 / 3$ & $1 / 2$ & 1 & 0.0470 \\
\hline \multicolumn{7}{r}{$\lambda=5.1022, C I=0.0256, R I=1.12, C R=0.0228<0.1$}
\end{tabular}

According to the expected career judgment matrix in Table 4 , the maximum eigenvalue is 5.1022 and the consistency index is 0.0256 by using matlab software, and then the 
consistency ratio is 0.0228 by comparing the random consistency index 1.12 .

(3) Secondary evaluation index judgment matrix

Table 5. Educational background A3.

\begin{tabular}{lllll}
\hline A3 & B11 & B12 & B13 & Weight \\
\hline B11 & 1 & 6 & $1 / 3$ & 0.2851 \\
B12 & $1 / 6$ & 1 & $1 / 8$ & 0.0623 \\
B13 & 3 & 8 & 1 & 0.6527 \\
\hline
\end{tabular}

$$
\lambda=3.0735, C I=0.0368, R I=0.58, C R=0.0634<0.1
$$

According to the educational background judgment matrix obtained in Table 5, the maximum eigenvalue of 3.0735 and consistency index of 0.0368 are calculated by using matlab software, and the consistency ratio is 0.0634 compared with random consistency index 0.58 .

\subsubsection{Analysis of Solution Results of Urban Talent Demand Model}

(1) Analysis and interpretation of primary evaluation indicators

According to the weight obtained by MATLAB, it is found that the indicators that have a great influence on the demand for talents are: expected occupation, educational background, and job demand [5].

(2) Analysis result and explanation of secondary evaluation index

According to the weight obtained by MATLAB, we know that the indexes which have great influence on the job demand and expected occupation are: economic management occupation, science and technology occupation, social security occupation, service occupation, other occupation. It is known that the major impact on the educational background is: undergraduate above, below undergraduate, unlimited education [6].

\section{Predict Talent Demand}

\subsection{Establish Arima Model}

According to section 2.1, we know that job requirements and expectations are divided into economic management [7], science and technology, social security, service, etc. Bachelor degree or less and no degree. We can use this system to assess which factors have the greatest impact on a city's talent needs. In order to predict China's talent demand more accurately, it is based on the national data and combined with the time series model to predict the potential talent demand of future cities [8]. In this paper, ARIMA model is used to predict urban talent demand in the next three years.

(1) Stationary recognition of sequences

Based on the data for 2016-2017, their time-based fluctuations were plotted [9]. If the individual value fluctuates around the average value of the sequence and there is no obvious upward or downward trend, it is proved that the stability of the given sequence is better. Below are the broken line diagrams of job requirements, expected occupation and educational background.

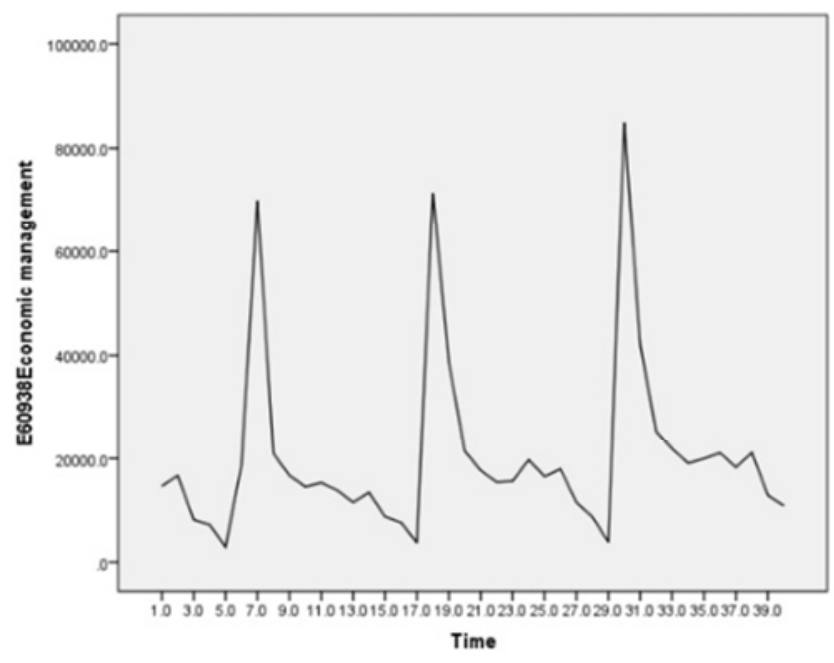

Figure 1. Economic management.

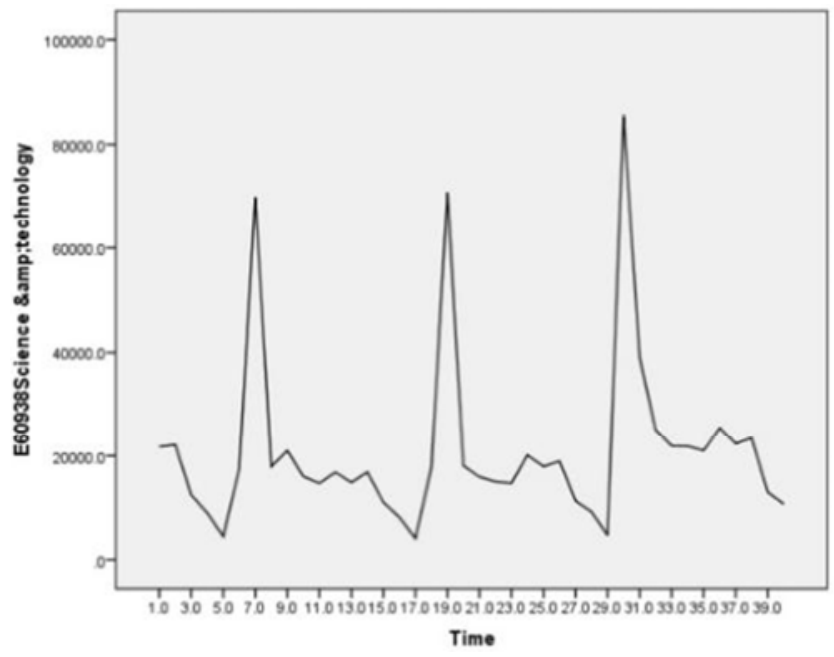

Figure 2. Science and technology.

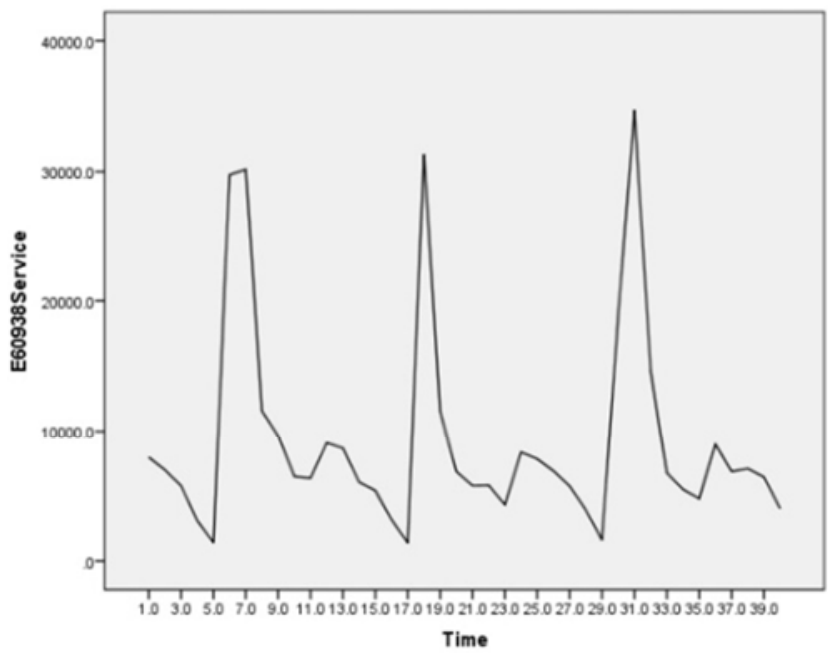

Figure 3. Service. 


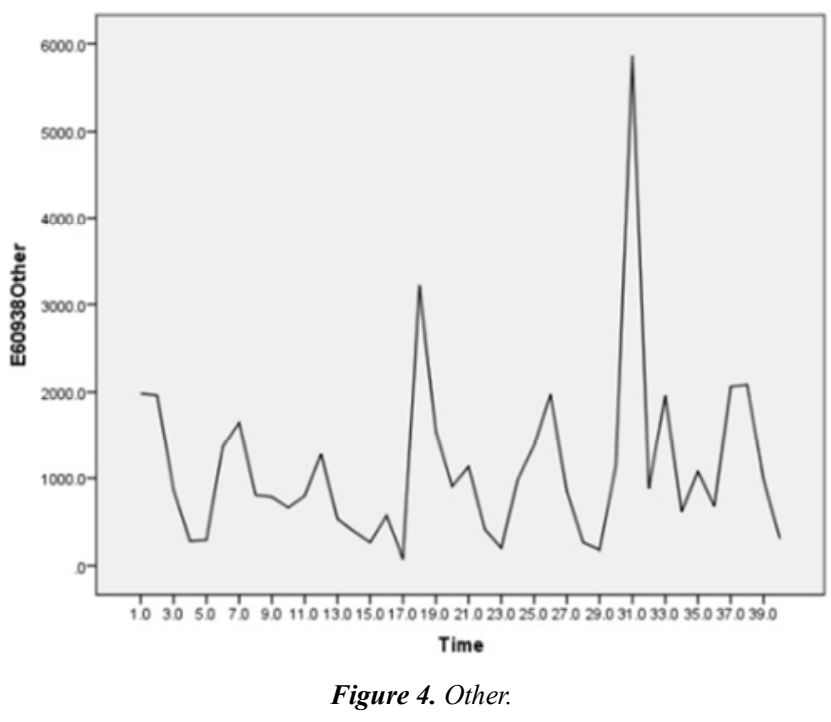

(2) Estimate the parameters of the model

The ARIMA model requires the sequence to be stationary, so it is necessary to analyze the stationarity of the data. The following is the stock sequence autocorrelation graph and partial autocorrelation graph to analyze the stability of the sequence. It can be seen from the graph that the sequence autocorrelation graph (ACF) and partial autocorrelation graph (PACF) are trailing, which shows that the sequence is non-stationary. However, the sequence is generally stable, so it can be further analyzed by difference.

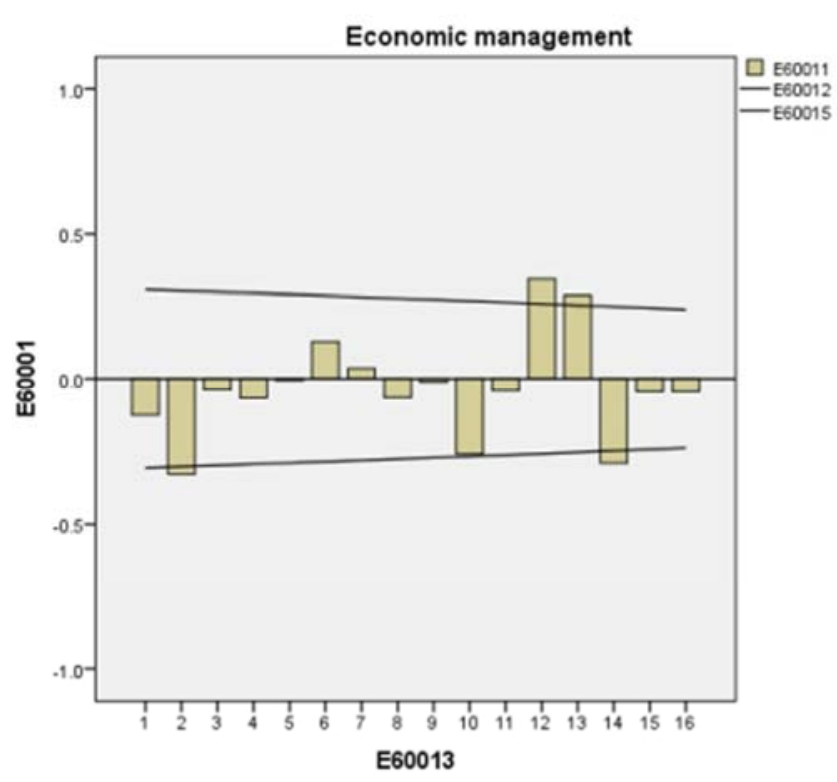

Figure 5. Autocorrelogram.

The sequence difference sequence diagram is drawn and its stability is observed. It can be seen from the graph that the difference sequence is basically uniformly distributed on both sides of the zero scale line, so the difference sequence can be considered to be stable.

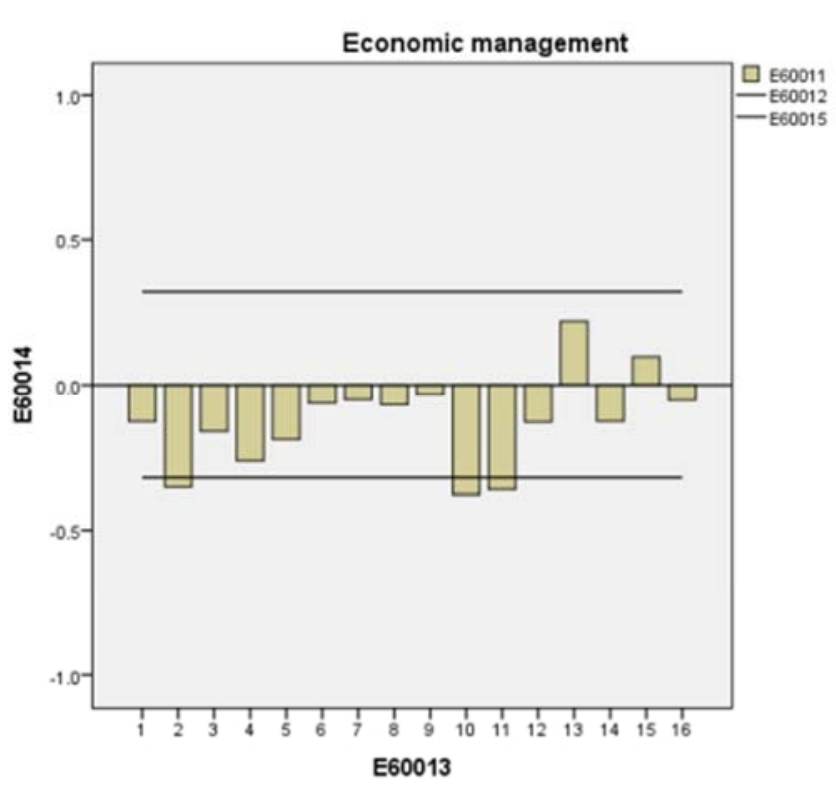

Figure 6. Partial autocorrelation graph.

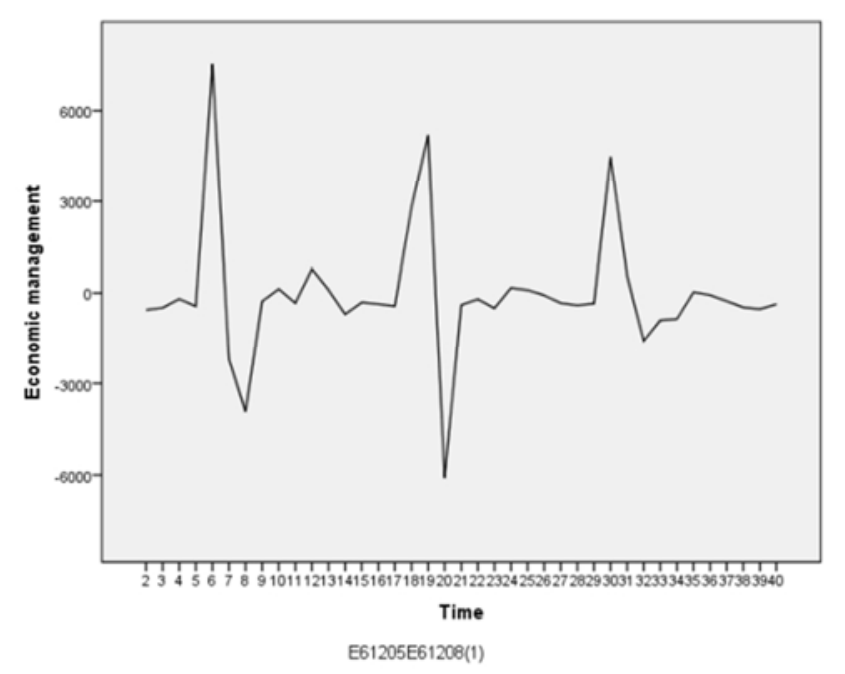

Figure 7. Difference sequence.

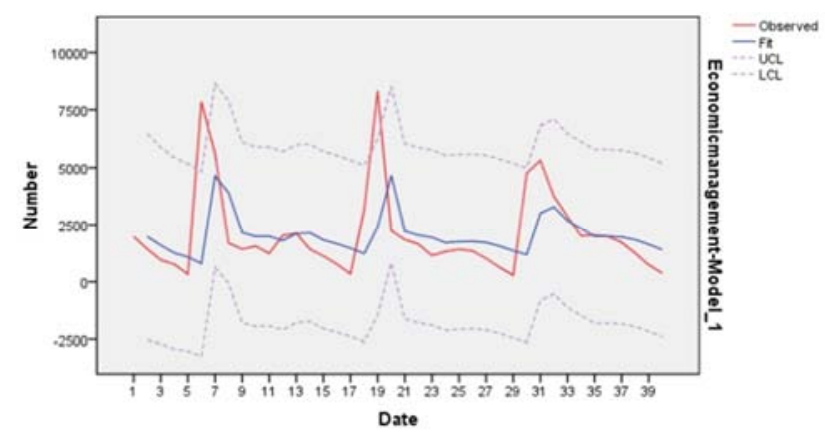

Figure 8. Sequence fitting data.

The autocorrelation analysis of time series prediction module includes the analysis of autocorrelation coefficient and partial correlation coefficient. After matlab calculation and repeated tests, the three estimation parameters of ARIMA model are determined as $\mathrm{D}=1$ and $\mathrm{Q}=1$. Then, the parameters are tested. The results show that the variance $(0.03826)$ and 
the standard error (0.051729) of the residual error series are given in the statistical scale of goodness of fit. These two values are small, which indicates that the prediction model is fitted well. The accuracy of the model is proved to be reliable.

\subsection{Model Solution}

Forecast domestic talent demand in the next three years, as shown in the following table.

(1) The desired occupation is shown in the table below.

Table 6. Desired profession.

\begin{tabular}{llllll}
\hline Time & $\begin{array}{l}\text { Economic } \\
\text { management }\end{array}$ & $\begin{array}{l}\text { Science and } \\
\text { technology }\end{array}$ & $\begin{array}{l}\text { Social } \\
\text { security }\end{array}$ & Service & Other \\
\hline 1 & 1982 & 732 & 437 & 270 & 170 \\
2 & 1433 & 709 & 401 & 128 & 249 \\
3 & 953 & 696 & 273 & 170 & 112 \\
\hline
\end{tabular}

(2) The work requirements are shown in the tablebelow.

Table 7. Job demand.

\begin{tabular}{llllll}
\hline Time & $\begin{array}{l}\text { Economic } \\
\text { management }\end{array}$ & $\begin{array}{l}\text { Science and } \\
\text { technology }\end{array}$ & $\begin{array}{l}\text { Social } \\
\text { security }\end{array}$ & Service & Other \\
\hline 1 & 14656 & 21791 & 10834 & 7978 & 1984 \\
2 & 16721 & 22178 & 8574 & 6985 & 1963 \\
3 & 8216 & 12395 & 5906 & 5754 & 862 \\
\hline
\end{tabular}

\section{Talent Introduction Strategy}

Quantitative analysis of some new job-hunting trends, such as civil service exams and studying abroad. With the change of time, these factors also show periodic changes, belonging to time series data [10]. Commonly used time series data processing methods include ARMA model, GARCH model, etc. In this paper, GARCH model is adopted to quantify employment trend factors. Aiming at the result of quantitative factors, the paper puts forward the targeted policies of investment attraction and urban development strategy [11].

\subsection{Analysis on the Change of New Job-seeking Tendency Factors}

Firstly, descriptive statistical analysis of the number of overseas students shows that with the change of years, the number of overseas students is gradually increasing [12]. This paper selects the data of the number of people going abroad from 2007 to 2016 for statistics, taking the year as the abscissa and the number of people going abroad as the ordinate, and the unit is 10,000 people. The final statistical results are shown in figure 9.

Secondly, descriptive statistical analysis of the number of students studying abroad shows that the number of students studying abroad fluctuates with the change of year. In this paper, the data of the number of people taking the national examination from 2007 to 2018 are selected for statistics, with the year as the abscissa and the number of people taking the national examination as the ordinate, and the unit is 10,000 people. The final statistical results are shown in figure 10 .

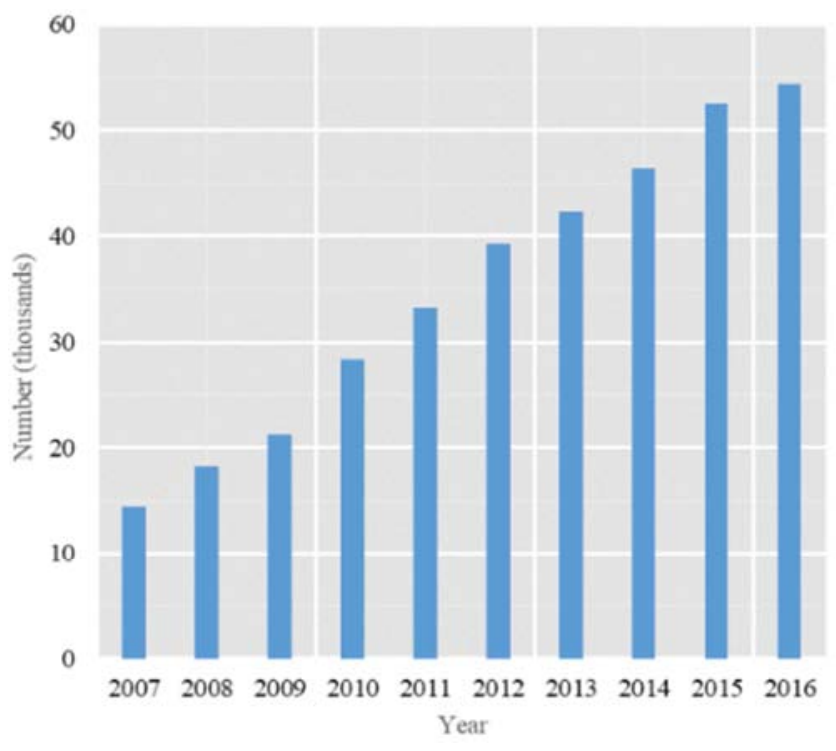

Figure 9. Statistics of the number of overseas students.

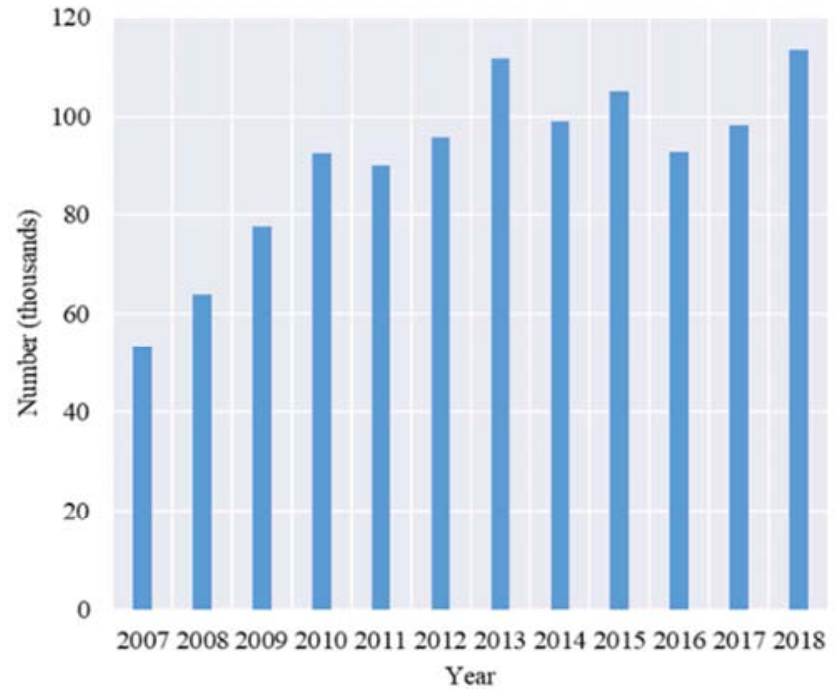

Figure 10. Statistics of the number of students taking examination.

The number of students taking the national examination shows a cyclical trend, but the overall trend is still on the rise.

\subsection{Urban Employment Quantification Based on GARCH Model}

\subsubsection{The GARCH Model}

GARCH model for the extension of the ARCH model, ARCH model for through the variance - average equation of simultaneous changes in continuity of feasibility is higher in data analysis, such as in the continuous time sequence estimation, consider the time shift effect, and joined the residual error correction, find out in a certain time and space distribution rule, and according to the accuracy prediction samples in a row. GARCH, in a broad sense, is to conduct simultaneous solution of data characteristic changes, and find a spectrum estimation of data change effects through 
parameter distribution. By combining mean term (time term) and variance term (intercept term), it eliminates the impact of trend, so that the accuracy is more reasonable. The formula is as follows:

$$
h_{t}=a_{0}+a_{1} e_{t-2}^{2}+a_{2} e_{t-2}^{2}+L+a_{p} e_{t-p}^{2}+\beta_{1} h_{t-1}+\beta_{2} h_{t-2}+L+\beta_{q} h_{t-q}
$$

Amongthem, $a_{0}>0$ and $a_{i} \geq 0, \quad i=1,2, L, p ; j=1,2, L, q$.

Assuming that the residual is subject to the distribution of the estimated coefficients in space and time, and that the sum of the estimated coefficients in the mean-variance of GARCH model is 1 , the formula can be converted into: $h_{t}=a_{1} e_{t-2}^{2}+a_{2} e_{t-2}^{2}+L+a_{p} e_{t-p}^{2}+\beta_{1} h_{t-1}+\beta_{2} h_{t-2}+$ $L+\beta_{q} h_{t-q}$, If and only if $a_{1}+a_{2}+L+a_{p}+\beta_{1}+\beta_{2}+$ $L+\beta_{q} h_{t-q}<1$, GARCH model is a standard GARCH model.

\subsubsection{Model Solution}

The GARCH model in this paper is simulated by using Eviews metering software, and the data collected above are substituted into it. The final parameter results were obtained and the parameters were statistically analyzed. The statistical results are shown in table 8.

Table 8. Model parameters.

\begin{tabular}{ll}
\hline Parameter & The parameter value \\
\hline$\mu$ & 392 \\
$a_{0}$ & 0.017 \\
$a_{1}$ & 0.06 \\
$\beta_{1}$ & 0.9413 \\
$v$ & 3.335 \\
\hline
\end{tabular}

\subsubsection{Stability Test}

If the VAR model established is stable, all the roots of the model will fall into the circle shown below. If the results show that some roots are not in the circle shown below, the model will be unstable and the running results will be invalid. All the roots of the model fall into the unit circle as shown in the figure below, which means that the modules of all the roots of the model are less than 1, indicating that the stability of the model passes the test.

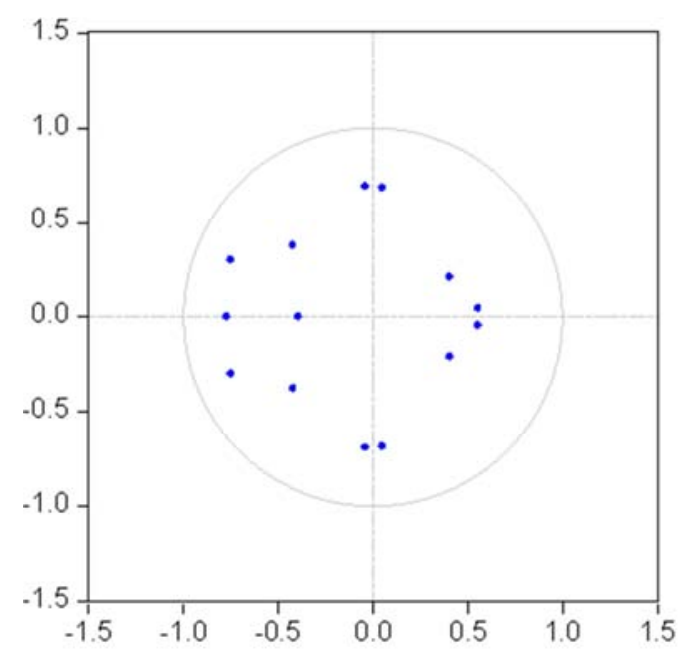

Figure 11. Stability test results.
Taking studying abroad and taking the national examination as an example, with the increase of years, both the people who choose to study abroad and those who choose to take the national examination generally show an upward trend [13]. Therefore, if we want to attract talents to the greatest extent, we should start from the three aspects of urban prospect, urban environment and urban talent security policy to attract talents to the greatest extent. For example, we will continue to create a more open environment for trade and investment, an environment suitable for industrial development with comprehensive costs, a more attractive environment for talent development, a more efficient and transparent environment for government affairs, a more beautiful and livable environment for green development, and a fair and just environment under the rule of law [14].

\section{Conclusion}

In the era of information technology, talents are the key to the development and competition of a city or even a country. At present, the influence of occupational preference, such as going abroad and participating in the national examination, will also affect the attraction of urban talents [15]. By determining the factors that affect the urban talent demand, this paper puts forward a new strategy for different types of talent demand in the next three years, which provides a certain reference for the study of urban and talent development.

\section{References}

[1] Yu Fei, Wang Huiqiang, Zhao Yanhong. Comprehensive Evaluation of talent attraction in Beijing-Tianjin-Hebei city group based on factor analysis [J]. Baoding College Journal, 2017, 30 (03): 36-40.

[2] Chen Lei. Quantitative Evaluation of The Attractiveness Evaluation of Urban Talents in China [J]. Business economy, 2018 (08): 43-45+59.

[3] Zheng Wei, Huang Xing, Xiao Yujie. Study of the forecasting model of commodity demand based on time series [J]. Journal of Chongqing Polytechnic University (Natural Science), 2019, 33 (09): 217-222.

[4] Jiang Tingting. Reflections on archives management in the talent market [J]. Acumen, 2018 (23): 221.

[5] Zheng Shaode. Improving the quality of talent cultivation in vocational schools based on industrial demand $[\mathrm{N}]$. Zhuhai special zone daily, 2018-11-21 (F02).

[6] Zhong Kun. On the supply and demand of college students' employment market $[\mathrm{J}]$. Economic and trade practice, 2017 (23): 340 .

[7] Zhang Shaoyong, Economic management and supervision of statistical work. Huang Qiang editor, xiamen special economic zone, yearbook, China statistical publishing house, 2017149-151, yearbook.

[8] Wang Limin. Research and Application of demand forecasting Model for Talent Market [D]. Hebei normal University, 2013. 
[9] Ye Jun. City talent dynamic comprehensive evaluation model of research [D]. Shenzhen university, 2017.

[10] Jia-lin Yang. Beijing talent gathered strength evaluation research [D]. The capital economic and trade university, 2016.

[11] Li Hua. Evaluation and comparison of talent attraction of xi 'an city [D]. Xi 'an university of science and technology, 2010.

[12] Hu Shunquan. Factors influencing the employment difficulty of local college graduates and countermeasures [J]. China adult education, 2018 (15): 85-86
[13] He Runfeng. Talents provide power source for urban development [N]. Lanzhou daily 2019-5-13 (006).

[14] Chen Feipeng. The way of talent driving urban development [N]. Taizhou daily 2019-09-09 (003).

[15] He Ping, Feng Yali. Improve talent attraction in hebei province empirical study [J]. Journal of hebei university adult education. 